B.I. Kuznetsov, T.B. Nikitina, A.V. Voloshko, I.V. Bovdyj, E.V. Vinichenko, B.B. Kobilyanskiy

\title{
SYNTHESIS OF AN ACTIVE SHIELDING SYSTEM OF THE MAGNETIC FIELD OF POWER LINES BASED ON MULTIOBJECTIVE OPTIMIZATION
}

Purpose. The synthesis of the active shielding systems by technogenic magnetic field generated by the different types of high voltage power lines in a given region of space using various cables of controlled magnetic field sources. Methodology. The initial parameters for the synthesis of active shielding system parameters are the location of the high voltage power lines with respect to the protected transmission line space, geometry and number of cables, operating currents, as well as the size of the protected space and normative value magnetic field induction, which should be achieved as a result of shielding. The objective of the synthesis of the active shielding system is to determine their number, configuration, spatial arrangement, wiring diagrams and compensation cables currents, setting algorithm of the control systems as well as the resulting value of the induction magnetic field at the points of the protected space. Synthesis of active shielding system is reduced to the problem of multiobjective nonlinear programming with constraints in which calculation of the objective functions and constraints are carried out on the basis of Biot - Savart Laplace law. The problem is solved by a stochastic multi-agent optimization of multiswarm of particles which can significantly reduce the time to solve it. Results. Active screening system synthesis results for the various types of transmission lines and with different amounts of controlled cables is given. The possibility of a significant reduction in the level of induction of the magnetic field source within a given region of space. Originality. For the first time carried out the synthesis of the active shielding systems, by magnetic field generated by the different types of high voltage power lines within a given region of space controlled by a magnetic field sources with different amounts of controlled cables. Practical value, Practical recommendations on reasonable choice of the number and spatial arrangement of compensating cables of active shielding systems for different types of high voltage power lines in order to ensure the effectiveness of a given shielding of the magnetic field high voltage power lines. References 13. figures 6 .

Key words: power lines, power frequency magnetic field, active shielding system, multiobjective synthesis, stochastic multiagent optimization, particle multiswarm.

Проведен синтез систем активного экранирования техногенного магнитного поля, создаваемого различными воздуиными линиями электропередачи внутри заданной области пространства, с помощьь управляемых источников магнитного поля. Синтез сводится к рещению задачи многокритериального нелинейного программирования с ограничениями, в которой вычисления целевых функций и ограничений выполняются на основании закона Био - Савара - Лапласа. Задача решается методом стохастической мультиагентной оптимизации мультироем частиц, что позволяет существенно сократить время решения. Приведены результаты синтеза систем активного экранирования для различных типов ЛЭП и с различным количеством управляемых обмоток. Показана возможность существенного снижения уровня индукции исходного магнитного поля внутри заданной области пространства. Библ. 13, рис. 6.

Ключевые слова: воздушные линии электропередачи, магнитное поле промышленной частоты, система активного экранирования, многокритериальный синтез, стохастическая мультиагентная оптимизация, мультирой частиц.

Introduction. Many residential buildings and structures are located in the vicinity of overhead power lines so that the level of the magnetic flux density inside them exceeds the current sanitary standards. In addition, due to the constant rise in price of land, the construction of residential, administrative and other public buildings in the places where the existing overhead power lines. One possible way of operation of such buildings is the use of active shielding systems.

Analysis of existing active shielding systems. The research and implement a variety of active shielding system of man-made magnetic field of industrial frequency currently underway intensively [1-9]. In such systems special coil are used as the executive body of the active shielding system - active cables, the number of which is determined by the specifics of the problem being solved. The most widely used active shielding system with a single coil. [1] To improve the efficiency of the system using two, three, six, twenty-four or more windings [9]. To control these windings can be used a different num- ber of magnetic field meters - magnetometers: one, two, three, six, twenty-four or more. Number magnetometers, usually equals to the number of controlled winding or number of windings pairs. Specifically, when six type coils Helmholtz coils may be used three magnetometers disposed at the center of the magnetic field shielding region and oriented orthogonally with respect to controlled windings [9].

The goal of the work is synthesis and study of systems of active shielding of the magnetic field of industrial frequency generated by a variety of transmission lines with different numbers of magnetic windings of the executive bodies and assessment of the effectiveness of the synthesized systems.

The formulation of the optimal control problem on the basis of multiobjective optimization. We consider the solution of the problem of synthesis of systems of active shielding of man-made magnetic field of industrial frequency generated by overhead lines within a given region of space, on the basis of multi-criteria approach.

(C) B.I. Kuznetsov, T.B. Nikitina, A.V. Voloshko, I.V. Bovdyj, E.V. Vinichenko, B.B. Kobilyanskiy 
[12] Technogenic magnetic field is generated by a threephase overhead power line. Active shielding of the magnetic field sensor system comprises a magnetic field control system, power source and controllable magnetic field source - controlled current windings installed in the zone where it is necessary to maintain the internal magnetic field parameters within specified limits.

At given structure of the system of active magnetic field shielding task active shielding system synthesis in a given space is reduced to the determination of the vector spatial location and geometric dimensions compensated coils, as well as the controller parameters $X$ at which the maximum value of the magnetic field at selected points $P_{i}$ of the considered space $P$ takes a minimum value

$$
X^{*}=\arg \min _{X \in X} \max _{P_{i} \in \boldsymbol{P}} B\left(X, P_{i}\right) .
$$

In minimizing the magnetic flux density $B\left(X, P_{i}\right)$ at the point $P_{i}$ induction values at other points of the space situated in the vicinity of this point is greater than this minimum value, or by undercompensation or by overcompensation level source magnetic field induction using active shielding system. Moreover, as we approach the point in question to the value of the control winding induction becomes significantly greater induction of the initial level of the magnetic field due to overcompensation. Therefore, the problem (13) can not be reduced to the solution of $m$ local minimize magnetic flux density problems $B\left(X, P_{i}\right)$ in $m$ points $P_{i}$

$$
X_{i}^{*}=\arg \min _{X \in \mathrm{X}} B\left(X, P_{i}\right), i=\overline{1, m},
$$

and then to the choice of such a solution $X^{*}$ from the set of $m$ local optima $X_{i}^{* *}, i=\overline{1, m}$ at which the maximum value of the magnetic flux density $B\left(X, P_{i}\right)$ in all the points $P_{i}$ is minimal

$$
X^{* *}=\arg \min _{i=1, m} \max _{j=1, m} B_{i j}^{*}\left(X_{i}^{*}, P_{j}\right),
$$

where $B_{i j}^{*}\left(X_{i}^{*}, P_{j}\right)$ is the magnetic flux density in the point $P_{j}$ calculated at the optimal value of the vector of the desired parameters of regulators $X_{i}^{*}$ found one that minimizes (3) the level of the induction at the point $P_{i}$.

In general, the problem (1) the synthesis of a system of active magnetic shielding power frequency field generated by overhead lines within a given region of space, can be formulated in the form of multi-criteria optimization problem following the vector criterion

$$
B(X)=\left[B\left(X, P_{1}\right), B\left(X, P_{2}\right) \ldots B\left(X, P_{m}\right)\right]^{T},
$$

whose components $B\left(X, P_{i}\right)$ is the vector of induction modules $m$ points $P_{i}$ of the considered space. This, of course, need to be considered limitations on vector control and state variables as a vector and the inequality may equality

$$
G(X) \leq G_{\max }, H(X)=0 .
$$

Note that the components of the vector criterion (4) and limitations (5) is a nonlinear function of the vector of the desired parameters of regulators $X$ and their calcula- tion is performed on the basis of the law of Biot-SavartLaplace $[10,11]$.

A method of solving the problem of multiobjective optimization. The problem of finding a local minimum of (4) at one point $P_{i}$ of the space, as a rule, is multiextremal containing local minima and maxima, therefore, to solve it is advisable to use multi-agent algorithms stochastic optimization [12]. Consider the algorithm for finding the set of Pareto-optimal solutions multicriteria problems of nonlinear programming based on multi-agent stochastic optimization. To date, we developed a large number of particle swarm optimization algorithms - PSO algorithms based on the idea of collective intelligence particle swarm like gbest PSO algorithms and lbest PSO [13]. Application of multi stochastic optimization methods for solving multicriteria problems today raises certain difficulties and this trend continues to grow rapidly [12, 13]. To solve the original multiobjective nonlinear programming problem (4) with constraints (5) construct an algorithm for stochastic optimization of multi-agent based on multiple swarms of particles, the number of which equals the number of components of the vector optimization criterion. In the standard particle swarm optimization algorithm changes velocities of the particles is carried out in a linear fashion. [13] To increase the speed of finding the global optimum algorithm used nonlinear stochastic optimization of multi-agent [12].

With the help of individual $j$-th swarms solved the problem of optimizing the scalar criteria $B\left(X, P_{j}\right)$ which are components of the vector optimization criterion (4). In order to find a global solution to the original multiobjective problem (4) in the search for optimal solutions to local criteria individual swarms exchange information with each other. At the same time to calculate particle swarm speed information is used on a global optimum, received particles of another swarm that allows you to select all of the potential Pareto optimal solutions. To this goal, at each step $t$ of $i$-motion of the particles of the $j$-th swarm functions swarm binary preferences of local solutions, received all the swarms. The solution $X_{j}^{*}(t)$ obtained during the optimization objective function $B\left(X(t), P_{j}\right)$ using the $j$-th swarm is preferred relative to the solution $X_{k}^{*}(t)$ resulting in the optimization of the objective function $B\left(X(t), P_{k}\right) \quad$ with the help of $k$-th swarm, i.e. $X_{j}^{*}(t) \succ X_{k}^{*}(t)$ if the following condition is correct

$$
\max _{i=1, m} B\left(P_{i}, X_{j}^{*}(t)\right)<\max _{i=1, m} B\left(P_{i}, X_{k}^{*}(t)\right) .
$$

At the same time as the global optimal solution $X_{k}^{*}(t)$ of the $k$-th swarm the global solution $X_{j}^{*}(t)$ is used, the resulting by $j$-th swarm which is more advantageous with respect to a global solution $X_{k}^{*}(t)$ of the $k$-th swarm on the basis of preference relation (6).

In fact, this approach is implemented the basic idea of the method of successive narrowing of the field of trade-offs - from the initial set of potential solutions based 
on the information about the relative importance of local solutions consistently removed all Pareto-optimal solutions, which can be selected according to the available information about the preferences of respect. Removal is carried out until the globally optimal solution. The application of this approach in each step is not the restriction is removed, no potentially optimal solution.

Results of computer modeling. We consider the synthesis of the active shielding system of the magnetic field generated by overhead lines of various design, within a given region of space controlled by a magnetic field sources with different amounts of compensating windings and various designs. At the beginning of the active system, consider shielding the magnetic field generated by double-circuit overhead lines having six conductors. As it has been shown by many researchers $[3,5]$, the magnetic field produced by such a line has an elliptical polarization, which allows to build active shielding system with one compensation winding. It should be noted that such systems are most widely in the world $[1,6,8]$. As an example, Fig. 1 shows the lines of equal levels of magnetic flux density with enabled active magnetic field shielding system with a single executive body of the magnetic coil. As can be seen from this Figure, in this space, where it is necessary to shield the magnetic field, while the system is active shielding level magnetic field does not exceed $0.4 \mu \mathrm{T}$, while the level of the source of the magnetic field varies in the range of $1.8 \mu \mathrm{T}$ to $0.5 \mu \mathrm{T}$.

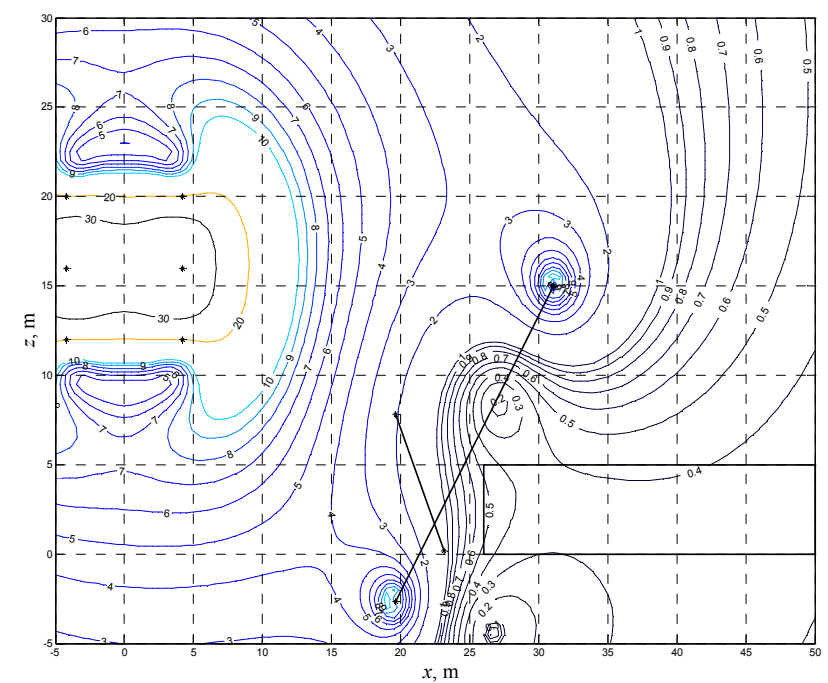

Fig. 1. The lines of equal level of magnetic flux density with enabled active shielding system with one winding

To improve the efficiency of the system will add a further winding, as shown in Fig. 2. In this system, the active layer shielding the magnetic field does not exceed 0.2 $\mu \mathrm{T}$, while the level of the magnetic field in a system with only one winding is reduced to $0.4 \mu \mathrm{T}$.

In the world practice of building systems in addition to the shielding of active single-phase three-phase windings are used as windings, allowing to create a rotating magnetic field, as shown in Fig. 3.

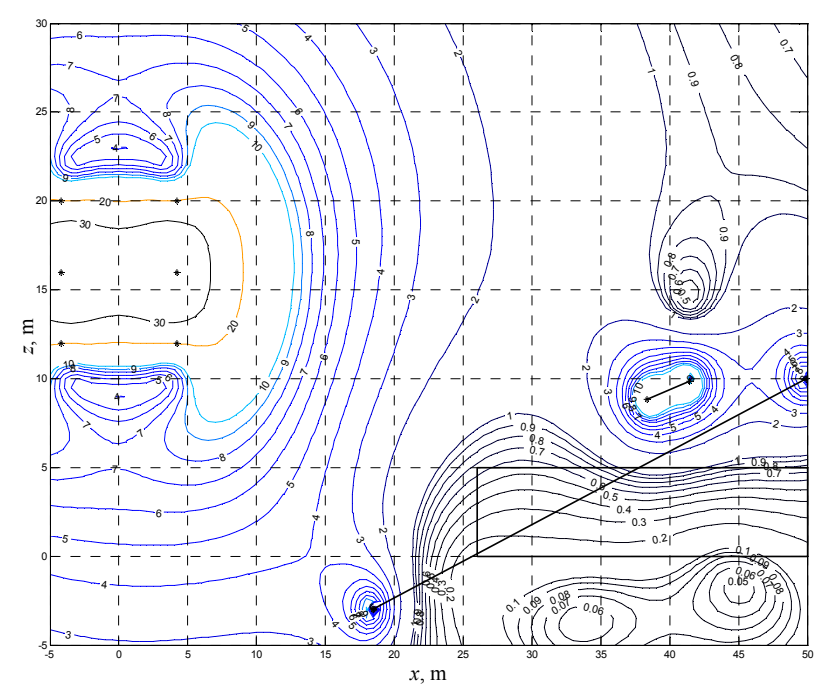

Fig. 2. The lines of equal level of magnetic flux density with enabled active shielding system with two windings

In this system, the magnetic field does not exceed the level of $0.4 \mu \mathrm{T}$, so that the system provides the same effectiveness as the system with a single winding, as shown in Fig. 1. However, in this case, three phase winding occupies less space than a single-phase winding at the same efficiency of the system.

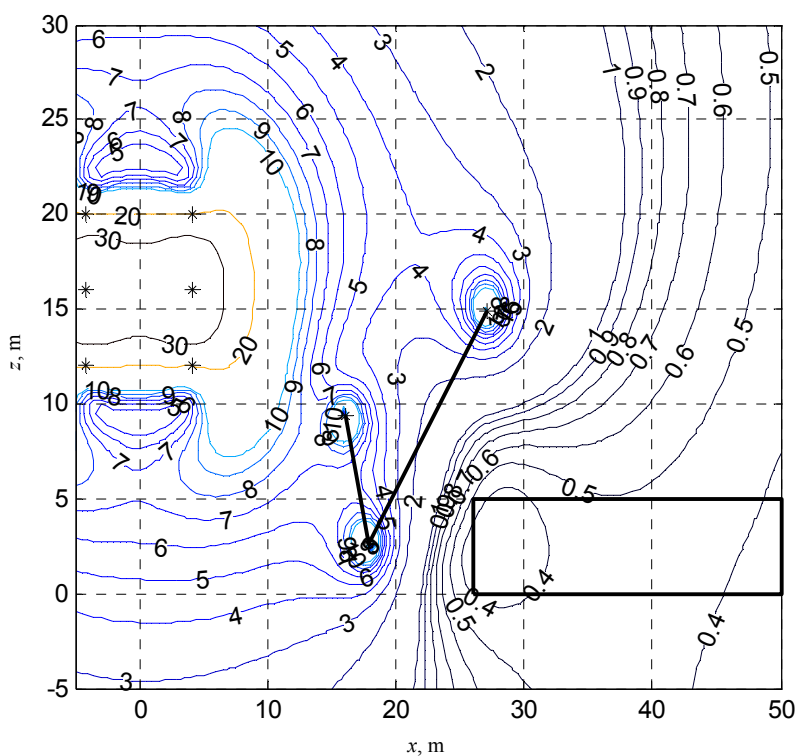

Fig. 3. The lines of equal level of magnetic flux density with enabled active shielding system with three-phase winding

Fig. 4 shows the lines of equal levels of magnetic flux density with enabled active shielding system using a three-phase and single-phase windings. The level of the magnetic field in such a system does not exceed $0.3 \mu \mathrm{T}$.

Let us now consider the synthesis of the active shielding system of the magnetic field generated by the single circuit overhead lines having three current-carrying wires. The magnetic field produced by such a line has a substantially circular polarization $[3,5]$, so that for the construction of active shielding system must use at least two compensation winding. 
Fig. 5 shows the lines of equal levels of magnetic flux density with enabled active shielding system with two windings.

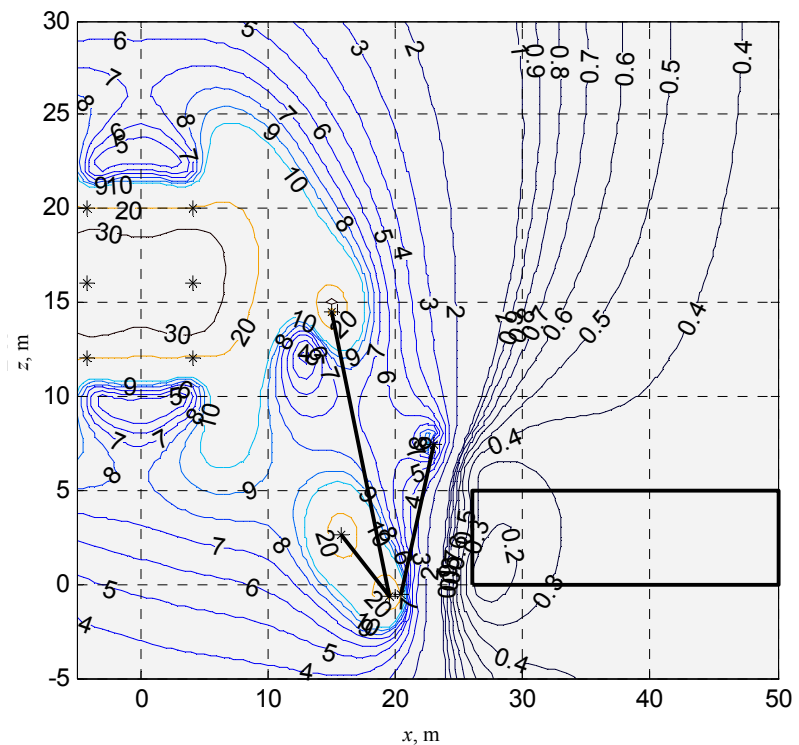

Fig. 4. The lines of equal level of magnetic flux density with enabled active shielding system with three-phase and one-phase windings

As it shown in Fig. 5, in this space, where it is necessary to shield the magnetic field, while the system is active shielding level magnetic field does not exceed 0.4 $\mu \mathrm{T}$, while the level of the source of the magnetic field varies in the range of $1.8 \mu \mathrm{T}$ to $0.5 \mu \mathrm{T}$.

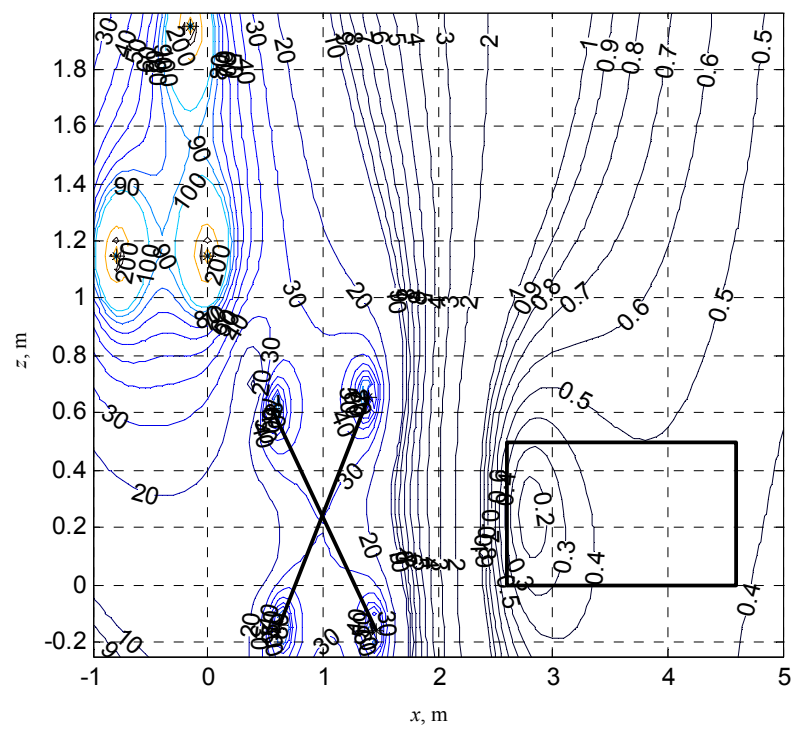

Fig. 5. The lines of equal level of magnetic flux density with enabled active shielding system with two windings

The magnetic field of the circular polarization can also create and use a three-phase winding, as shown in Fig. 6. The level of the magnetic field in such a system does not exceed $0.4 \mu \mathrm{T}$.

\section{Conclusions.}

1. It is shown that the problem of the synthesis of the active shielding system is reduced to the problem of multiobjective linear programming with restrictions in which calculation of the objective functions and constraints are carried out on the basis of the Biot-Savart-Laplace law.

2 . It is proposed to implement the solution of the synthesis problem based on constructing Pareto optimal solutions using multi-agent algorithms of stochastic optimization by a particle multiswarm which reduces the time for solving the problem.

3. The possibility of reducing the level of the magnetic flux density inside a given region of space using the synthesized active shielding system four times is confirmed.

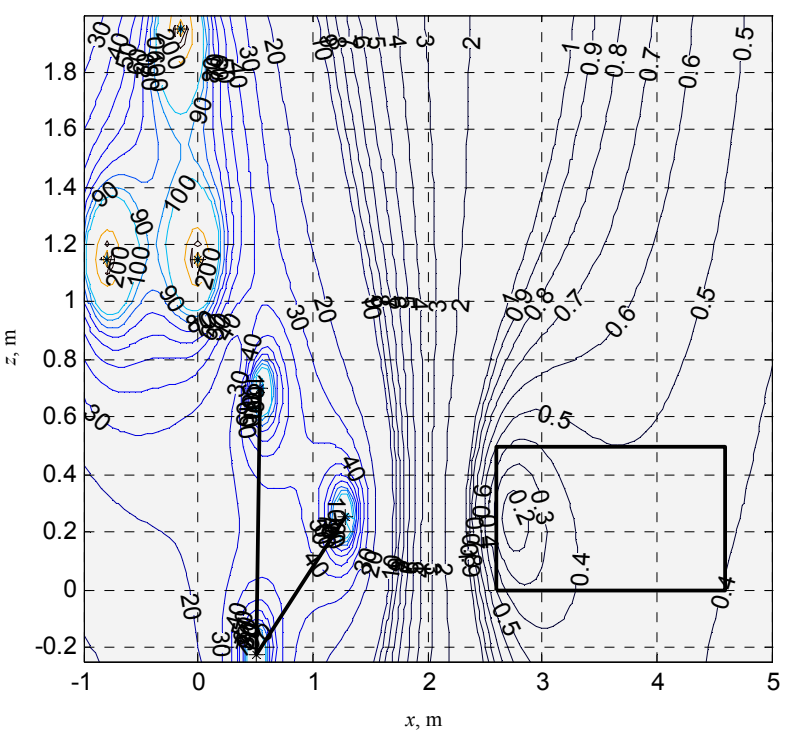

Fig. 6. The lines of equal level of magnetic flux density with enabled active shielding system with three-phase winding

\section{REFERENCES}

1. Active Magnetic Shielding (Field Cancellation). Available at: http://www.emfservices.com/afcs.html (accessed 10 September 2012).

2. Beltran H., Fuster V., García M. Magnetic field reduction screening system for a magnetic field source used in industrial applications. 9 Congreso Hispano Luso de Ingeniería Eléctrica (9 CHLIE), Marbella (Málaga, Spain), 2005, pp. 84-99.

3. Celozzi S., Garzia F. Active shielding for power-frequency magnetic field reduction using genetic algorithms optimization. IEE Proceedings - Science, Measurement and Technology, 2004, Vol.151, no.1, pp. 2-7. doi: 10.1049/ip-smt:20040002.

4. Ter Brake H.J.M., Wieringa H.J., Rogalla H. Improvement of the performance of a mu -metal magnetically shielded room by means of active compensation (biomagnetic applications). Measurement Science and Technology, 1991, Vol.2(7), pp. 596601. doi: 10.1088/0957-0233/2/7/004.

5. Yamazaki K., Kato K., Kobayashi K. MCG Measurement in the environment of active magnetic shield. Neurology and Clinical Neurophysiology, 2004, Vol. 40, pp. 1-4.

6. Celozzi S. Active compensation and partial shields for the power-frequency magnetic field reduction. Conference Paper of IEEE International Symposium on Electromagnetic Compatibility. Minneapolis (USA), 2002, Vol.1, pp. 222-226. doi: 10.1109/isemc.2002.1032478.

7. Shenkman A., Sonkin N., Kamensky V. Active protection from electromagnetic field hazards of a high voltage power line. HAIT Journal of Science and Engineering. Series B: Applied Sciences and Engineering, Vol. 2, Issues 1-2, pp. 254-265.

8. Ter Brake H.J.M., Huonker R., Rogalla H. New results in active noise compensation for magnetically shielded rooms. 
Measurement Science and Technology, 1993, Vol. 4, Issue 12, pp. 1370-1375. doi: 10.1088/0957-0233/4/12/010.

9. Kazuo Kato, Keita Yamazaki, Tomoya Sato, Akira Haga, Takashi Okitsu, Kazuhiro Muramatsu, Tomoaki Ueda, Masahito Yoshizawa. Shielding effect of panel type active magnetic compensation. IEEJ Transactions on Fundamentals and Materials, 2005, Vol. 125, Issue 2, pp. 99-106. doi: 10.1541/ieejfms.125.99.

10. Rozov V.Yu., Reutskyi S.Yu. Pyliugina O.Yu. The method of calculation of the magnetic field of three-phase power lines. Tekhnichna elektrodynamika, 2014, no.5, pp. 11-13. (Rus).

11. Nikolova N.K., Bakr M.H. Electromagnetics I. Matlab Experiments Manual for EE2FH3. Department of Electrical and Computer Engineering McMaster University, 2012. 96 p.

12. Clerc M. Particle Swarm Optimization. London, ISTE Ltd., 2006. 244 p. doi: $\mathbf{1 0 . 1 0 0 2 / 9 7 8 0 4 7 0 6 1 2 1 6 3 . ~}$

13. Gazi V., Passino K.M. Swarm Stability and Optimization. Springer, 2011. 318 p. doi: 10.1007/978-3-642-18041-5.

Received 15.09.2016

How to cite this article:

Kuznetsov B.I., Nikitina T.B., Voloshko A.V., Bovdyj I.V., Vinichenko E.V., Kobilyanskiy B.B. Synthesis of an active shielding system of the magnetic field of power lines based on multiobjective optimization. Electrical engineering $\&$ electromechanics, 2016, no.6, pp. 26-30. doi: 10.20998/2074-272X.2016.6.05.
B.I. Kuznetsov ${ }^{1}$, Doctor of Technical Science, Professor, T.B. Nikitina ${ }^{2}$, Doctor of Technical Science, Professor,

A.V. Voloshko ${ }^{1}$, Candidate of Technical Science,

I.V. Bovdyj ${ }^{1}$, Candidate of Technical Science,

E.V. Vinichenko ${ }^{1}$, Candidate of Technical Science,

B.B. Kobilyanskiy ${ }^{1}$, Candidate of Technical Science, Associate

Professor,

${ }^{1}$ State Institution «Institute of Technical Problems

of Magnetism of the NAS of Ukraine»,

19, Industrialna Str., Kharkiv, 61106, Ukraine,

phone+38050 5766900, e-mail: bikuznetsov@mail.ru

${ }^{2}$ Kharkov National Automobile and Highway University, 25, Petrovskogo Str., Kharkov, 61002, Ukraine, e-mail: tatjana55555@gmail.com 